\title{
REFLEXÃO E DIÁLOGO SOBRE SUSTENTABILIDADE NO ENSINO BÁSICO E SUPERIOR
}

\author{
Ana Carolina Barbosa de Souza ${ }^{1}$ \\ Norma Barbado ${ }^{2}$
}

\section{RESUMO}

Este estudo teve como objetivo promover o diálogo e a reflexão sobre sustentabilidade a partir de conhecimentos prévios dos estudantes da Educação Básica e do Ensino Superior no Instituto Federal do Paraná, Campus Umuarama. Trata-se de uma pesquisa-ação que teve início com um diagnóstico, composto por 8 questões, aplicado a uma amostra de 36 discentes, formando três grupos focais: 1) 10 estudantes do Ensino Médio (Educação Básica); 2) 21 estudantes de Graduação (Ensino Superior); 3) 5 estudantes do Mestrado em Sustentabilidade (Ensino Superior stricto sensu). Partindo desse diagnóstico, foi organizada uma palestra interativa para provocar a reflexão e o diálogo sobre sustentabilidade com os três grupos reunidos. Observou-se que os estudantes do Ensino Superior, especialmente os mestrandos, apresentaram maior conhecimento a respeito do assunto. Além disso, a interação entre estudantes de diferentes níveis de ensino foi benéfica, visto que as controvérsias e consensos relacionados à sustentabilidade puderam ser discutidos entre os atores do estudo e a literatura.

Palavras-chave: educação ambiental; ensino formal; pesquisa-ação; palestra interativa.

\section{REFLECTION AND DIALOGUE ON SUSTAINABILITY IN PRIMARY AND FURTHER EDUCATION}

\section{ABSTRACT}

This study aimed to promote dialogue and reflection on sustainability based on previous knowledge of students in primary and further education at the Federal Institute of Paraná Campus Umuarama. It is an action research initiated with a diagnosis, composed of eight questions, applied to a sample of 36 students, forming three focus groups: 1) Ten high school students (primary education); 2) Twenty-one undergraduate students (further or college education); 3) Five students of the Masters in Sustainability (further education Stricto sensu Based on this diagnosis, an interactive lecture was organized to provoke reflection and dialogue on sustainability with the three groups gathered. It was observed that further education students, especially master's students, had greater knowledge on the subject. In addition, the interaction between students of different levels of education was beneficial, since the controversies and consensuses related to sustainability could be discussed between the actors of the study and the literature.

Keywords: environmental education; formal education; action research; interactive lecture.

Recebido em: $16 / 6 / 2020$

Aceito em: $1 \% / 10 / 2020$

\footnotetext{
Instituto Federal do Paraná - IFPR, campus Umuarama/PR. Rodovia PR-323 - Parque Industrial. Umuarama/PR, Brasil. CEP 87507-014. http://lattes.cnpq.br/4329027954043815. https://orcid.org/0000-0001-7563-193X. anacarolinabarbosasf@gmail.com

2 Autora correspondente. Instituto Federal do Paraná - IFPR. Rodovia PR-323, Parque Industrial. Umuarama/PR, Brasil. CEP 87507-014. http://lattes.cnpq.br/8503890458095202. https://orcid.org/0000-0002-0562-3958.norma.barbado@ifpr.edu.br
} 


\section{INTRODUÇÃO}

Muitas questões relacionadas à sustentabilidade têm se tornado alvo de discussões ao longo de décadas no mundo contemporâneo, principalmente em razão das preocupantes questões ambientais. A partir do século passado ocorreram diversas conferências nacionais e internacionais e a humanidade pôde acompanhar as consequências de um sistema subsecivo da Revolução Industrial. Esse sistema focava apenas na produtividade, com o intuito de aumentar o crescimento econômico, deixando a qualidade do meio ambiente em péssimas condições. Nesse contexto, os eventos colocaram em pauta as possíveis formas de reparação e prevenção para os problemas já existentes, destacando-se formas de evitar possíveis catástrofes futuras (POTT; ESTRELA, 2017).

Em razão do estilo de vida das pessoas e dos conflitos relacionados ao meio ambiente, incluindo os problemas climáticos e socioambientais, tornou-se imprescindível a busca por melhorias nesse âmbito, com a urgente mudança para hábitos sustentáveis. $A$ questão ambiental pode comprometer as presentes e futuras gerações, afetando todos os seres vivos do planeta. A utilização exacerbada dos recursos naturais faz com que o planeta, que mantém o ser humano, tenda a não querer mais a presença do homem, como se ele fosse um corpo estranho (ROOS; BECKER, 2012).

Nesta reflexão, muito se usa a expressão "desenvolvimento sustentável" como uma aliada para resolver problemas sociais e ambientais, na diminuição dos impactos causados pelos seres humanos, porém "uma análise mais aprofundada revela uma falta de consenso, não somente quanto ao adjetivo sustentável, como também quanto ao desgastado conceito de desenvolvimento" (DIEGUES, 1992, p. 1).

Por um lado, é necessário traçar planos de sustentabilidade, encontrando meios de produzir, distribuir e consumir os recursos de forma mais coesiva, com eficácia econômica e viabilidade ecológica (BARBOSA, 2008). Por outro lado, há um equívoco do desenvolvimento sob a ótica da sustentabilidade. Assim, aprender a lidar com a complexidade dos problemas de sustentabilidade é um desafio, principalmente no que respeita à adaptação das necessidades de consumo da população ao universo em que ela está inserida e do qual depende (BONOTTO et al., 2018).

O conceito de "tripé da sustentabilidade" está ligado às esferas ambientais, econômicas e sociais como dimensões integradas, com mesma importância, que precisam interagir holisticamente (ELKINGTON; ROWLANDS, 1999; HORN et al., 2014). Essa tridimensionalidade, no entanto, apesar de atrativa, abrange diferentes setores, geralmente com uma visão ideologicamente comprometida com o capitalismo responsável pela degradação (FOLADORI, 2002).

Um tema relevante e prioritário nas discussões da maioria das instituições é a Educação Ambiental (EA), frequentemente complementada com "para sustentabilidade" (BARRETO; VILAÇA, 2018). Nesse sentido, as instituições direcionadas à educação, ambiente e desenvolvimento de alguns países tendem a substituir a concepção de EA por uma nova proposta de "educação para a sustentabilidade" ou para "um futuro sustentável" (LIMA, 2003).

A EA foi inserida no ensino por meio da Lei Federal No 9.795/99, que instituiu a Política Nacional de Meio Ambiente. Em seu artigo 2으, cita que a EA deve estar presente em todos os níveis e modalidades do ensino, seja ela de caráter formal ou não formal (BRASIL, 1999). Nesse contexto, destaca-se que 
a Política Nacional de Educação Ambiental é uma proposta programática de promoção da educação ambiental em todos os setores da sociedade. Diferente de outras leis, não estabelece regras ou sanções, mas estabelece responsabilidades e obrigações. Ao definir responsabilidades e inserir na pauta dos diversos setores da sociedade, a Política Nacional de Educação Ambiental institucionaliza a educação ambiental, legaliza seus princípios, a transforma em objeto de políticas públicas, além de fornecer à sociedade um instrumento de cobrança para a promoção da educação ambiental (EFFTING, 2007, p. 20).

Nessa direção, surgem as seguintes interrogações: Como se encontra o conhecimento dos estudantes do Instituto Federal do Paraná (IFPR), Campus Umuarama, sobre questões relacionadas à sustentabilidade? Como articular a discussão e a reflexão sobre sustentabilidade na Educação Básica e Superior da referida instituição? Diante de tais preocupações, este estudo teve como objetivo principal promover o diálogo e a reflexão sobre sustentabilidade a partir de conhecimentos prévios de estudantes da Educação Básica e do Ensino Superior do IFPR Campus Umuarama.

\section{MATERIAL E MÉTODOS}

Este estudo foi realizado no ano de 2019, no Instituto Federal do Paraná (IFPR) Campus Umuarama, autorizado pelo Comitê de Ética na Pesquisa (CEP/IFPR), com o parecer $n^{\circ}$ 3.532.018. Esta instituição é voltada ao Ensino Básico, Técnico e Tecnológico, com ofertas de cursos de nível médio, integrado e superior (Graduação e Pós-Graduação).

Neste trabalho, optou-se pela pesquisa descritiva no intuito de descrever as características de uma amostra de estudantes do IFPR Campus Umuarama, envolvendo o uso de técnicas padronizadas de coleta de dados: questionário e observação sistêmica (KAUARK; MANHÃES; MEDEIROS, 2010). Dessa forma, o diagnóstico inicial envolveu a interrogação direta dos participantes (36 discentes voluntários) por meio de um questionário eletrônico, contendo 8 questões de múltipla escolha (Quadro 1).

Quadro 1 - Diagnóstico aplicado aos estudantes do IFPR Campus Umuarama

\section{Questão 1. Qual é o meio de transporte que mais consome energia (combustível)?}
a) carro
b) navio
c) caminhão
d) avião

Questão 2. O que é "pegada ecológica"?
a) É uma metodologia que busca examinar quanto uma determinada empresa é ecológica.
b) É uma metodologia que busca examinar quais os impactos ambientais causados por produtos de difícil decomposição.
c) É uma metodologia que busca examinar como a forma de vida das pessoas deixa rastros e marcas no meio ambiente.
d) Todas as alternativas estão corretas.

\section{Questão 3. O que é consumo verde?}
a) É aquele em que o consumidor só compra produtos cujas embalagens são recicláveis.
b) É aquele em que o consumidor dá preferência a produtos e serviços que não agridam o meio ambiente, tanto na produção, quanto na distribuição, no consumo e no descarte final. c) É aquele em que o consumidor só compra produtos com embalagens na cor verde, por entender que eles são ecologicamente corretos.
d) É aquele em que o consumidor deixa de comer carne e se torna vegetariano. 


\section{Questão 4. Qual dos gases não é conhecido como um dos gases do efeito estufa (GEE)?}
a) $\mathrm{N}_{2} \mathrm{O}$ - óxido nitroso.
c) $\mathrm{CO}_{2}$ - dióxido de carbono ou gás carbônico.
b) $\mathrm{O}_{2}$ - oxigênio
d) $\mathrm{CH}_{4}$ - metano.

Questão 5. Os recursos naturais são finitos. Entre as opções qual recurso é o mais prejudicado atualmente?
a) Água
b) Petróleo
c) Carvão mineral
d) Gás natural

Questão 6. Assinale as formas incorretas de descarte dos medicamentos? I. No lixo comum; II. No vaso sanitário; III. Em água corrente; IV. Devolução à indústria farmacêutica.
a) I e II
b) I, II, III
c) I, II e III
d) I, III e IV

Questão 7. A respeito do consumo de energia no Brasil, assinale verdadeiro ou falso. "Cada consumidor brasileiro desperdiça em média $10 \%$ da energia fornecida".
a) Verdadeiro
b) Falso

\section{Questão 8.0 que é sustentabilidade?}

a) Ações e atividades humanas que visam a suprir as necessidades atuais da sociedade, sem comprometer o futuro das próximas gerações.

b) Fato de poder usar regularmente um recurso natural para o crescimento de uma empresa ou indústria.

c) Ações que levam ao crescimento e desenvolvimento da comunidade sem elevado custo financeiro para a sociedade.

d) Tudo aquilo que sustenta o cotidiano socioeconômico de um país.

Fonte: Autoria própria.

As questões foram direcionadas para averiguar o grau de conhecimento básico sobre questões a serem discutidas posteriormente. Assim, cada grupo focal (Quadro 2), em um Laboratório de Informática, teve um tempo aproximado de 30 minutos para responder às questões sem fonte de consulta. Após a análise dos resultados obtidos, os dados foram expressos em porcentagem.

Quadro 2 - Grupos focais constituídos por estudantes do IFPR Campus Umuarama para reflexão e diálogo sobre sustentabilidade

\begin{tabular}{|c|c|c|c|}
\hline $\begin{array}{c}\text { Grupo } \\
\text { Focal }\end{array}$ & Curso & Nível & $\begin{array}{c}\text { Número de } \\
\text { participantes }\end{array}$ \\
\hline $\mathbf{1}$ & $\begin{array}{c}\text { Programa de Mestrado em } \\
\text { Sustentabilidade (PSU - IFPR/UEM) }\end{array}$ & $\begin{array}{c}\text { Educação Superior } \\
\text { (Stricto sensu) }\end{array}$ & 5 \\
\hline $\mathbf{2}$ & Licenciatura em Química & $\begin{array}{c}\text { Educação Superior } \\
\text { (Graduação) }\end{array}$ & 21 \\
\hline $\mathbf{3}$ & $\begin{array}{c}\text { Técnico em Informática Integrado ao } \\
\text { Ensino Médio }\end{array}$ & Educação Básica & 10 \\
\hline
\end{tabular}

Fonte: Autoria própria.

Na sequência, partiu-se para uma atividade de pesquisa-ação, em que pesquisadores e discentes voluntários foram envolvidos em uma palestra participativa (KAUARK; MANHÃES; MEDEIROS, 2010) com os três grupos focais reunidos. Vale ressaltar que a pesquisa-ação pode ter diversas combinações, desde que não aconteça nenhuma contradição com a metodologia em questão (BARBIER, 2007; THIOLLENT, 2011). Assim, priorizou-se o processo de sensibilização ambiental dos três grupos focais (Quadro 1), 
conforme as deficiências verificadas no diagnóstico. A palestra foi proferida por um estudante do PSU (IFPR/UEM), da turma 2018, que realizou várias provocações aos grupos focais.

\section{RESULTADOS E DISCUSSÃO}

Com as respostas obtidas no diagnóstico inicial, percebeu-se certa racionalidade ambiental e alguns saberes em relação à sustentabilidade. É importante ressaltar, porém, que conhecer sobre questões socioambientais não significa que os discentes realizam práticas sustentáveis a fim de diminuir os impactos no meio ambiente. $O$ modo de vida capitalista urbano-industrial, em conformidade com o atual modelo de desenvolvimento econômico e tecnológico, é um grande responsável pelos impactos ambientais (PHILIPPI JUNIOR; PELICIONI, 2014). Assim, promover ações de sensibilização ambiental é fundamental para fazer florescer o sentido de pertencimento do sujeito. Dessa forma, por meio de atividades de educação ambiental no ensino formal, o estudante pode conhecer seu espaço, investigar, explorar e despertar sua curiosidade em relação aos recursos naturais (SILVA; SANTOS; TERÁN, 2019). Tal sensibilização ambiental pode promover o sentimento de cuidado, afeto, amor, respeito e pertencimento com o meio ambiente, propiciando mudanças de atitude e comportamento em relação aos problemas socioambientais do planeta (TIRIBA, 2018).

Em relação ao questionamento a respeito dos meios de transporte e o consumo de energia (Figura 1), observou-se que o assunto precisava ser mais abordado tanto no Ensino Superior (Grupos 1 e 2) quanto na Educação Básica (Grupo 3). A demanda por combustíveis fósseis, principalmente o petróleo, causa problemas ambientais desde a sua exploração e captação até sua etapa final. Quando são utilizados como fontes de energia, liberam gases que intensificam o efeito estufa, além de prejudicar a saúde humana (ANDRADE; SANTOS, 2015).

\section{Figura 1 - Porcentagens de acertos da questão "Qual é o meio de transporte que mais} consome energia (combustível)?". Resposta correta: d) avião.

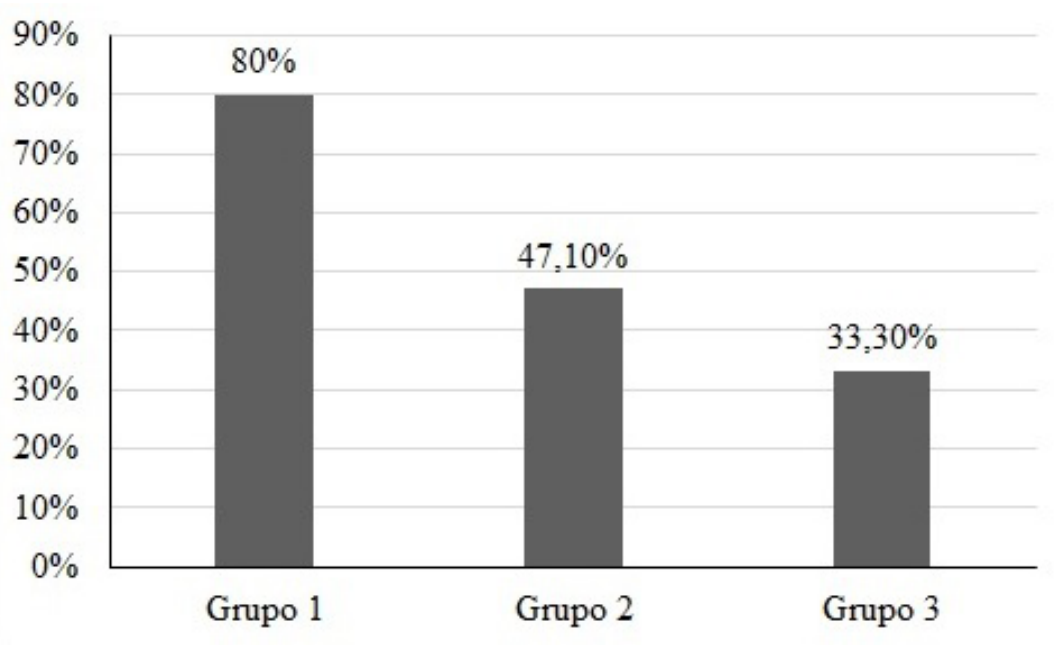

Fonte: Autoria própria. 
Quando perguntados sobre o conceito de pegada ecológica (Figura 2), é notável que os estudantes do Mestrado (Grupo 1) já possuíam afinidade com o assunto, diferentemente dos estudantes da Graduação (Grupo 2) e da Educação Básica (Grupo 3), que apresentaram dificuldades. Nesta questão verificou-se que os discentes, em sua maioria, possuem uma visão de que esse conceito está relacionado com metodologias que buscam examinar o quanto uma empresa é ecológica, ou ainda, que pegada ecológica se relaciona com examinar os impactos causados por produtos de difícil decomposição. A pegada ecológica, no entanto, é constituída por metodologias realizadas a partir de cálculos para saber a área de terreno produtivo, necessária para atender à demanda do estilo de vida da sociedade atual (CÉZAR-MATOS, 2009). Os seres humanos, como os demais seres vivos, precisam de uma quantidade mínima desses recursos para a sua sobrevivência. Nessa direção, a pegada ecológica é "[...] um instrumento que contabiliza os fluxos de matéria e energia que entram e saem de um sistema econômico, convertendo-os em área correspondente de terra ou água existentes na natureza para sustentar esse sistema" (VAN BELLEN, 2006). Dessa forma, ela se fundamenta na base da sustentabilidade, que consiste em atender às necessidades da sociedade atual sem comprometer as necessidades das futuras gerações.

Figura 2 - Porcentagens de acertos da questão "O que é "pegada ecológica?". Resposta correta:

c) É uma metodologia que busca examinar como a forma de vida das pessoas deixa rastros e marcas no meio ambiente

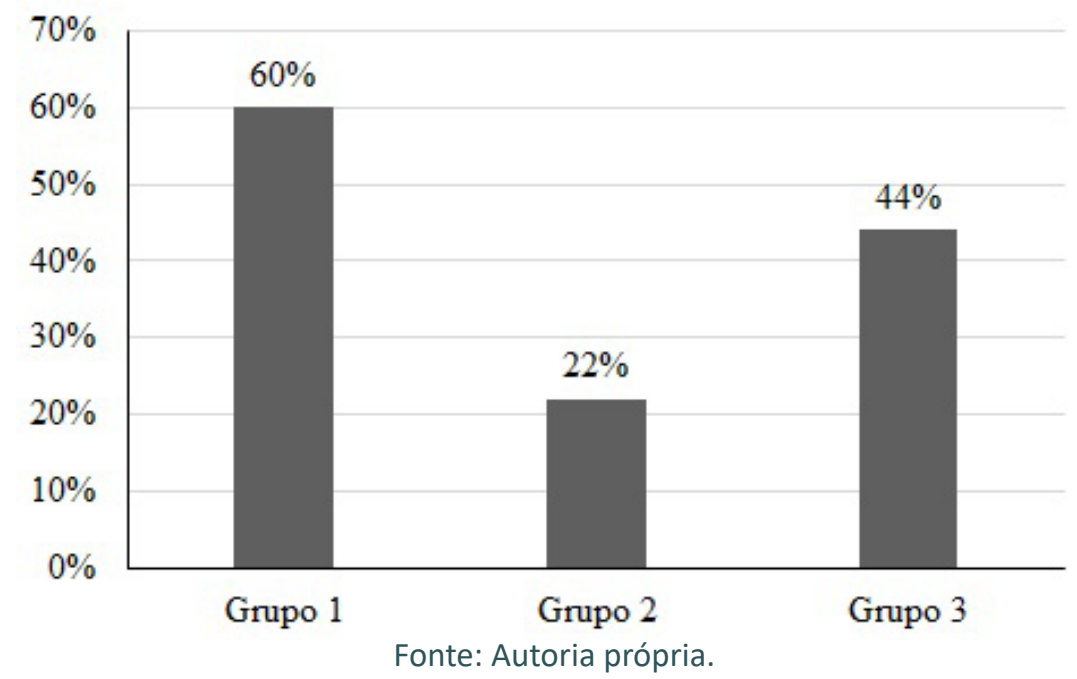

Seguindo com o diagnóstico, o questionamento a respeito do conceito de consumo verde (Figura 3) promoveu uma reflexão acerca dos produtos que os consumidores dão preferência, não apenas buscando os melhores preços, mas igualmente aqueles que menos provocam impactos ao meio ambiente em todos os seus estágios, desde sua compra até o seu descarte final. Neste quesito observou-se que tanto na Educação Básica quanto no Ensino Superior os estudantes do IFPR Campus Umuarama estão atentos. Com a estratégia do consumo verde, cresce cada vez mais o número de pessoas preocupadas com as questões ambientais. Essa ideia começou a ser difundida pelos grandes setores empresariais, que propagaram a ambientalidade de suas empresas ao notar a demanda por produtos ecológicos. A partir daí, aumentou a preocupação e a sensibili- 
zação sobre o impacto ambiental relacionado ao estilo de compras que os consumidores vinham realizando, havendo um aumento na opção por deixar de comprar produtos luxuosos que demandam muitos recursos para a sua fabricação (PORTILHO, 2005). Contrapondo a isso, essas propostas possuem uma série de limitações, uma vez que não atendem a todas as classes sociais, devido ao elevado preço desses produtos. Isso limita o poder de escolha, ou seja, há uma desigualdade de acesso. Além disso, não refletem a diminuição efetiva de consumo levando à cultura de reciclagem, que favorece a descartabilidade dos produtos consumidos. Por fim, há uma transferência de responsabilidade por parte do governo e das empresas para o cidadão (CAMARGO; VELHO, 2012).

Figura 3 - Porcentagens de acertos da questão "O que é consumo verde?". Reposta correta:

b) É aquele em que o consumidor dá preferência a produtos e serviços que não agridam o meio ambiente, tanto na produção, quanto na distribuição, no consumo e no descarte final

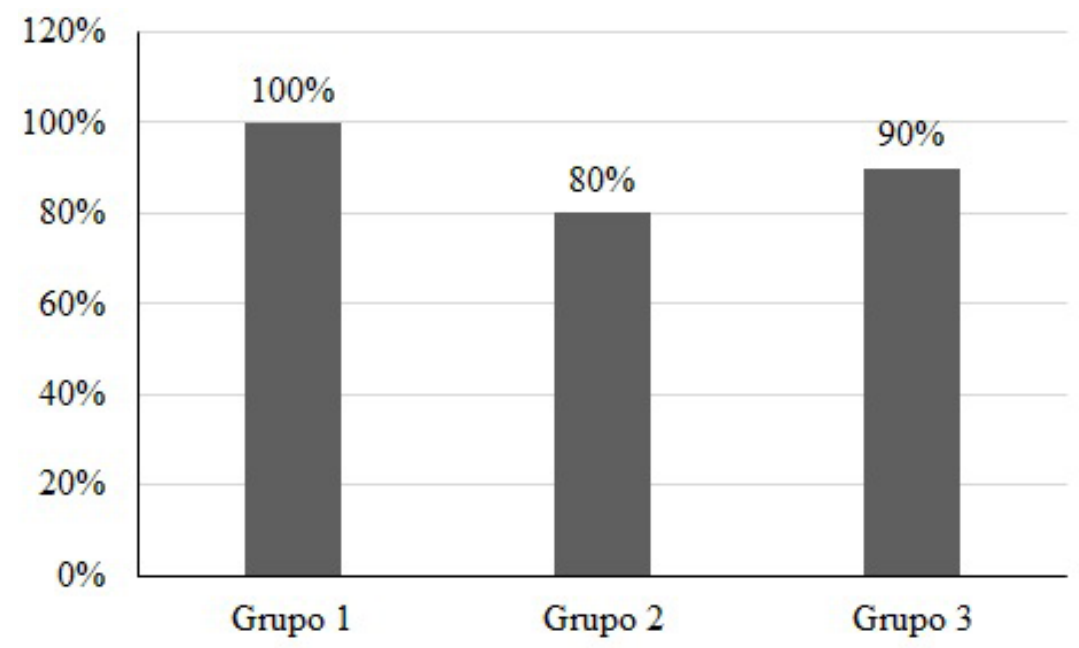

Fonte: Autoria própria.

Quando perguntados a respeito de qual gás presente na atmosfera não fazia parte dos gases do efeito estufa (GEE) (Figura 4), em que a resposta correta seria a alternativa b) $\mathrm{O}_{2}$ - oxigênio, percebeu-se, exceto nos mestrandos (Grupo 1), deficiência neste conteúdo. Estudos do International Geosphere-Biosphere Programme (IGBP) demonstram que o aumento dos indicadores que causam a destruição das florestas, a extinção de espécies e interferem no ciclo da água, geralmente ocorrem devido às ações antrópicas (MOREIRA JÚNIOR et al., 2017). Tais indicadores podem ser analisados por meio dos principais GEEs, o dióxido de carbônico, o metano e compostos nitrogenados. Vale destacar que o óxido nitroso $\left(\mathrm{N}_{2} \mathrm{O}\right)$ e o metano $\left(\mathrm{CH}_{4}\right)$ são considerados os principais GEEs, por que possuem uma alta capacidade de aquecimento e o seu tempo de fixação na atmosfera é maior. $\mathrm{O}$ metano $\left(\mathrm{CH}_{4}\right)$ origina-se principalmente da pecuária e do tratamento de resíduos, os quais emitem cerca de $20 \%$ dos gases causadores do efeito estufa. 0 óxido nitroso $\left(\mathrm{N}_{2} \mathrm{O}\right)$ representa cerca de $10 \%$ das emissões brutas e estão relacionadas principalmente com a adubação de solo, tanto por fertilizantes quanto por excrementos de animais. Já o dióxido de carbono $\left(\mathrm{CO}_{2}\right)$ representa cerca de $69 \%$ da emissão derivada da queima de combustíveis fósseis (RAMIRES, 2014). 
Figura 4 - Porcentagens de acertos da questão "Qual dos gases não é conhecido como um dos gases do efeito estufa (GEE)?". Resposta correta: b) $\mathrm{O}_{2}$ - oxigênio

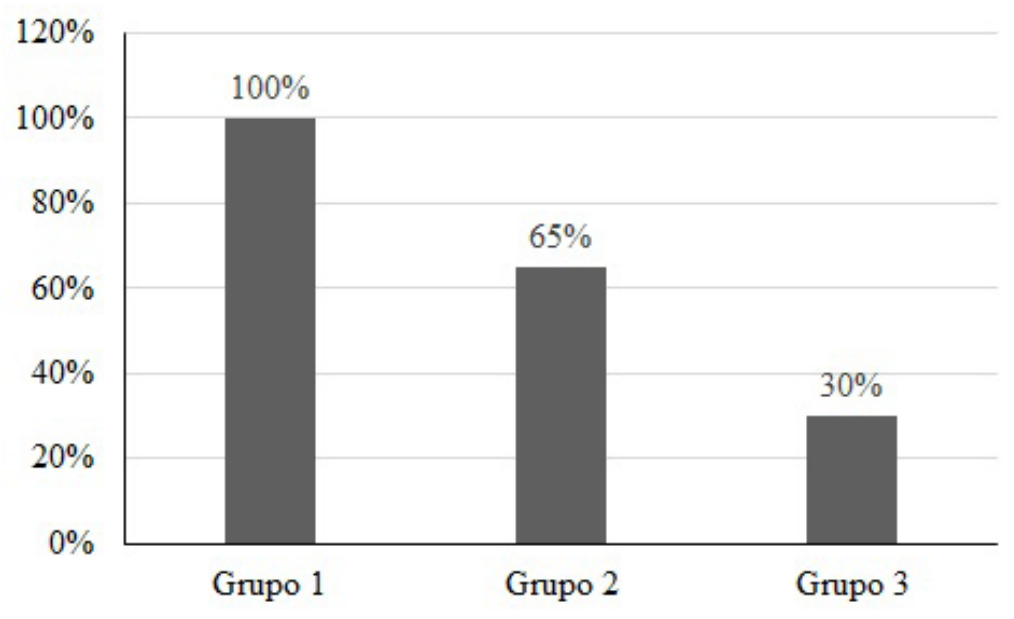

Fonte: Autoria própria.

Ainda no diagnóstico percebeu-se que a maioria dos estudantes sabia que a água é o recurso natural mais prejudicado atualmente (Figura 5). Vale ressaltar que o aumento à ameaça da falta de água deve-se aos efeitos do rápido crescimento da população mundial (RIBEIRO; ROLIM, 2017). Segundo o Instituto Internacional de Pesquisa de Política Alimentar, até 2050 aproximadamente 4,8 bilhões de pessoas estarão em situação de estresse hídrico, ou seja, caso em que a oferta de água disponível para consumo não conseguirá suprir a demanda existente, imperando, assim, um déficit (SEGALA, 2012). Essa questão é muito relevante, uma vez que o uso indiscriminado da água em residências, agricultura, grandes indústrias, além da destruição dos mananciais por meio da degradação das matas ciliares, favorecem esses dados alarmantes. No Brasil, é evidente que não há uma distribuição uniforme de água dos corpos hídricos. Várias cidades de diferentes regiões, principalmente do Nordeste, convivem com essa realidade, passando por racionamento hídrico ou a própria ausência de água, necessitando de caminhões-pipa para o abastecimento populacional (RIBEIRO; ROLIM, 2017).

Figura 5 - Porcentagens de acertos da questão "Os recursos naturais são finitos. Entre as opções qual recurso é o mais prejudicado atualmente?"

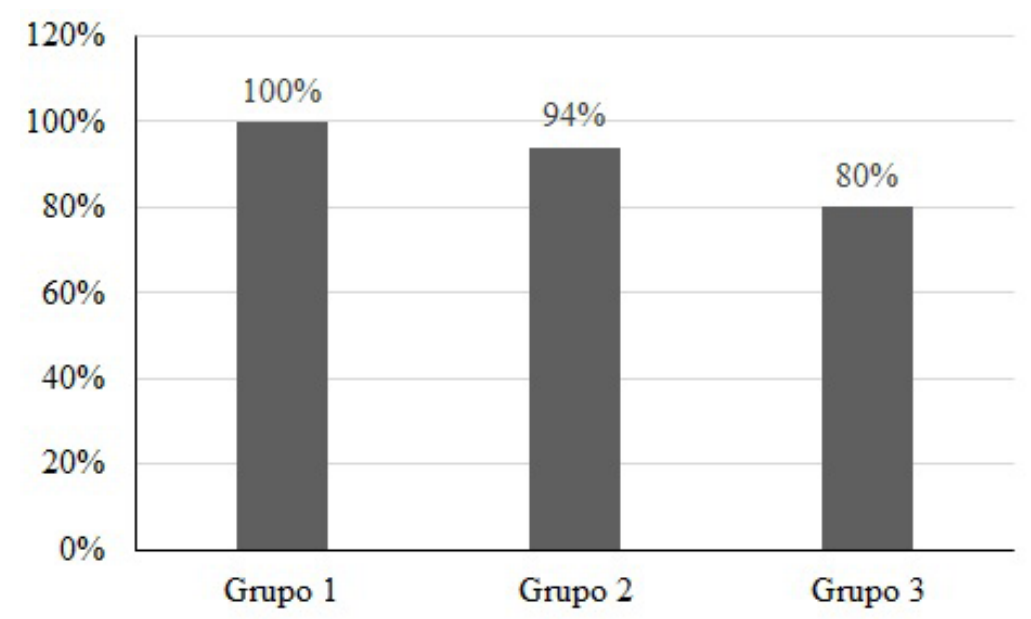

Fonte: Autoria própria. 
Em se tratando de poluição de solo e água, os discentes também foram questionados a respeito do descarte incorreto de medicamentos (Figura 6). Nesta questão percebeu-se maior deficiência nos estudantes do Mestrado (Grupo 1) e maior conhecimento nos estudantes do Ensino Médio (Grupo 3), o que sugere a boa qualidade deste conteúdo trabalhado na Educação Básica do IFPR. O desconhecimento e a falta de orientação do poder público podem ser causados pela escassez de campanhas explicativas sobre as consequências do descarte inadequado desse tipo de resíduo (PINTO et al., 2014), além da carência do assunto na educação formal.

Vale ressaltar que o descarte inadequado de medicamentos pode provocar a contaminação do solo e da água, além da bioacumulação. Eles são considerados resíduos químicos que, quando expostos a diversas condições, como temperatura, umidade e luz, podem transformar-se em substâncias tóxicas, prejudicando o meio ambiente de diversas maneiras, além de favorecer o surgimento de bactérias resistentes quando se trata de antibióticos (PINTO et al., 2014). Essa preocupação vale para todas as classes de medicamentos, fármacos quimioterápicos que geram resíduos pertencentes ao Grupo $B$, considerados perigosos, pois oferecem riscos à saúde pública e ao meio ambiente (ALMEIDA; WILSON; PETERLINI, 2016).

Figura 6 - Porcentagens de acertos da questão "Assinale as formas incorretas de descarte dos medicamentos? I. No lixo comum; II. No vaso sanitário; III. Em água corrente; IV. Devolução à indústria farmacêutica.". Resposta correta: b) I, II, III

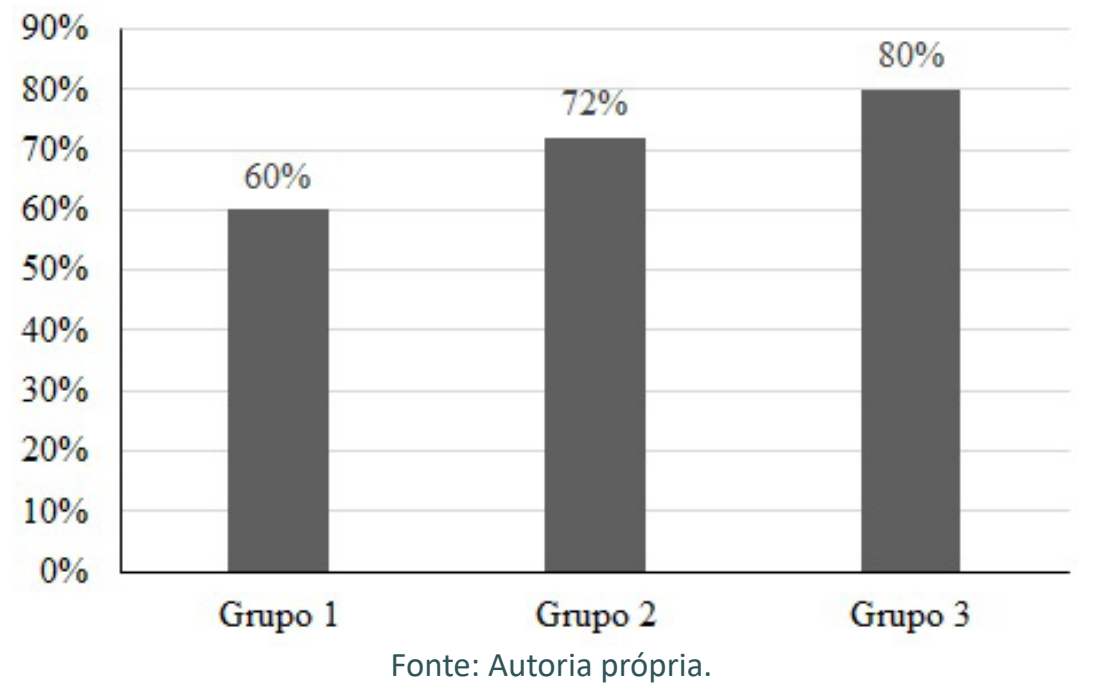

Destaca-se ainda que, no Brasil, a partir da Lei Federal № 12.305 de 2010, que instituiu a Política Nacional dos Resíduos Sólidos (PNRS), iniciou-se a exigência do Plano de Gerenciamento de Resíduos Sólidos (PGRS), que "é um documento que define diretrizes de gerenciamento ambientalmente adequado de todos os resíduos que são gerados no estabelecimento, determinando estratégias de controle e monitoramento dos processos produtivos" (SOUZA, 2017, p. 5). Por meio da referida Lei, todos os resíduos devem ser de responsabilidade compartilhada, a partir de um acordo setorial que deve ser firmado entre o poder público e fabricantes, importadores, distribuidores ou comerciantes (BRASIL, 2010). Sendo assim, os resíduos de medicamentos podem ser encaminhados às farmácias e hospitais para que tais instituições os encaminhem aos fabricantes, responsáveis pelo seu descarte final. 
Outra questão deste estudo foi a respeito do consumo de energia no Brasil (Figura 7), verificando-se maior quantidade de erros no Ensino Médio (Grupo 3). Esse questionamento buscou proporcionar uma reflexão acerca da quantidade de energia desperdiçada, embora a maioria das pessoas só perceba isso quando o valor da sua conta mostra-se alto. Segundo o Ministério do Meio Ambiente, o desperdício de energia elétrica, seja pelo uso de eletrodomésticos inadequados ou por péssimos hábitos de consumo, aumenta em média 3\% ao ano em todos os setores (industrial, residencial e comercial). Destaca-se ainda que uma grande quantidade de recursos naturais não renováveis é explorada e utilizada para geração de energia elétrica; além do mais, a construção de usinas hidrelétricas causa impactos maiores ao meio ambiente (OLIVEIRA, 2013).

Figura 7 - Porcentagens de acertos da questão "A respeito do consumo de energia no Brasil, assinale verdadeiro ou falso: Cada consumidor brasileiro desperdiça em média $10 \%$ da energia fornecida". Resposta correta: a) Verdadeiro.

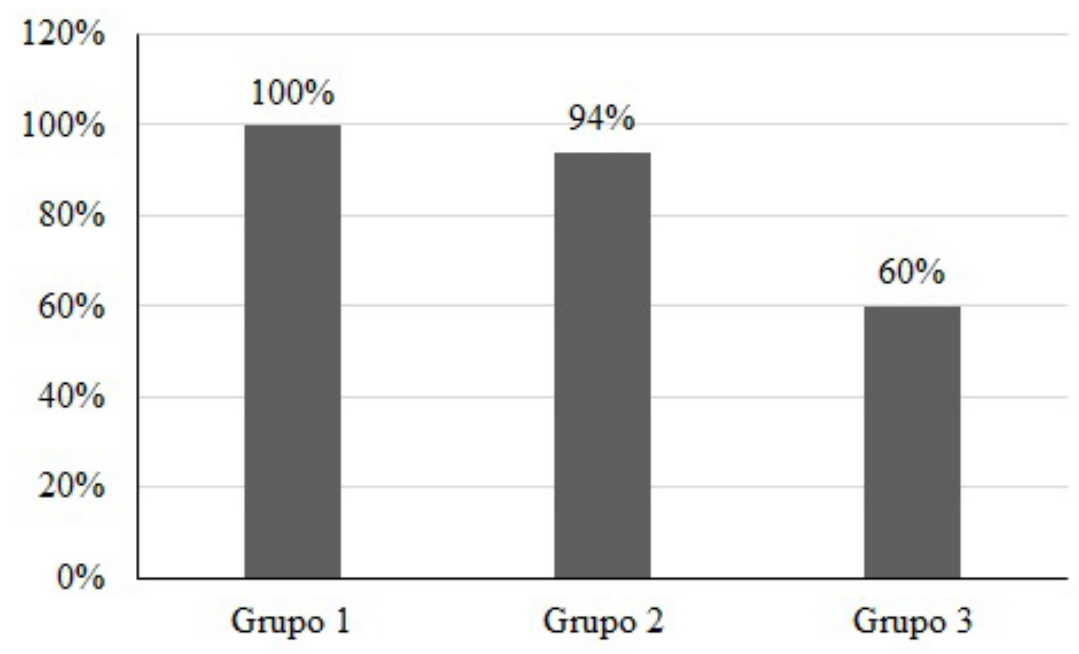

Fonte: Autoria própria.

Após questionar os discentes sobre os temas anteriormente relacionados, foi perguntado a eles se sabiam a definição da palavra sustentabilidade (Figura 8). Com a maioria dos acertos, percebeu-se que há uma noção do assunto avaliado. Fato relevante, uma vez que a sustentabilidade surgiu como uma necessidade para ajudar a enfrentar os diversos problemas decorrentes do crescimento da população mundial e da economia, fundamentada no aumento do consumo dos recursos naturais, essenciais a todas as formas de vida (SILVA et al., 2017). 
Figura 8 - Porcentagens de acertos da questão "O que é sustentabilidade?".

Resposta correta: a) Ações e atividades humanas que visam a suprir as necessidades atuais da sociedade, sem comprometer o futuro das próximas gerações.

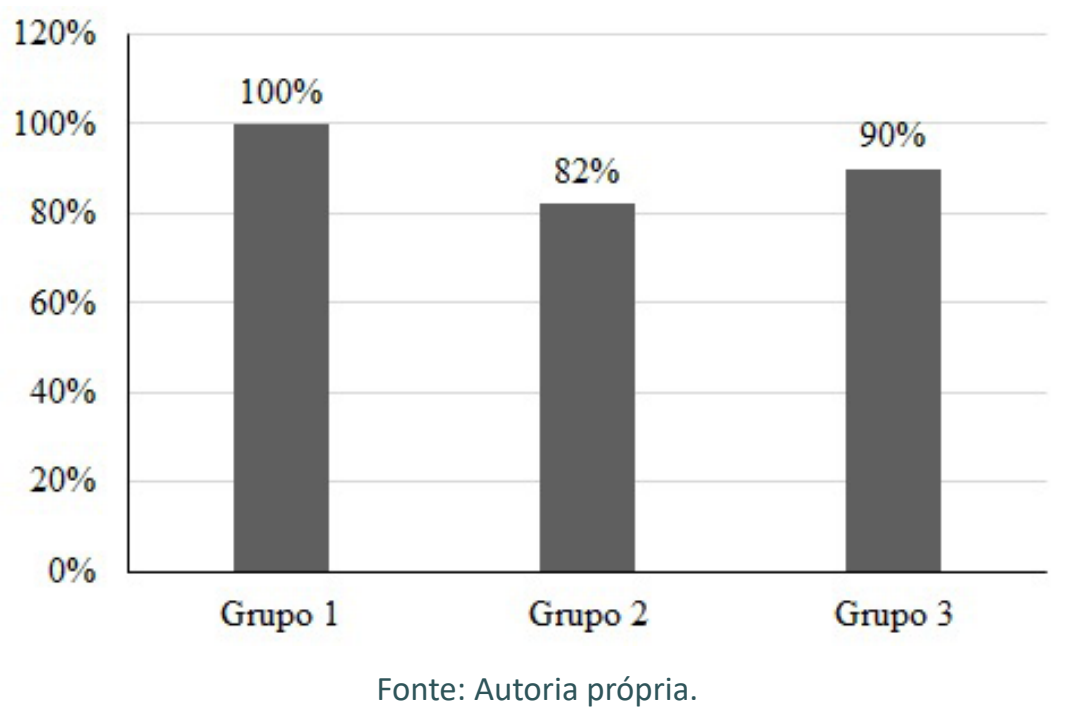

Há, entretanto, diferentes visões e dimensões desse conceito, principalmente em sua versão crítica, quando se refere ao modelo de desenvolvimento sustentável. Esse princípio, que deveria promover um equilíbrio entre os âmbitos social, econômico, político, ambiental e cultural, geralmente é o oposto, tornando-se predatório em relação aos recursos naturais. Assim, esse discurso pode tornar-se excludente, gerando desigualdade social, desemprego, concentração de riquezas, contribuindo para a extrema pobreza, contrapondo-se aos seus princípios e valores (ANTUNES; NASCIMENTO; QUEIROZ, 2017).

Nesse contexto, a palestra interativa sobre a temática para os três grupos focais foi de extrema relevância. A técnica do grupo focal permitiu interações grupais ao se discutir questões sobre sustentabilidade, além de possibilitar a compreensão das percepções, das atitudes e das representações sociais (VEIGA; GONDIM, 2001; GONDIM, 2003). Na palestra inicialmente foi abordada a concepção de vários autores sobre os conceitos que caracterizam a sustentabilidade, destacando-se os aspectos do seu tripé (sociais, ambientais e econômicos), numa reflexão crítica. A partir disso foi traçada uma linha do tempo, em que foram apresentadas informações a partir da pré-História, como a descoberta da germinação de sementes, passando pela expansão da agricultura, chegando aos dias atuais.

O relato referente à história dos antepassados teve a finalidade de indicar que, a partir desses processos, os seres humanos já vinham, desde a Antiguidade, degradando o ambiente. Nessa época a população era bem menor, as pessoas viviam em pequenos grupos, os quais se fixavam em determinados locais, usufruíam dos recursos disponíveis que, ao findar, provocavam a migração, ocasionando uma devastação por onde passavam. Destacou-se também que, a partir do surgimento da agricultura e da pecuária, o meio ambiente começou a ser mais prejudicado, as populações começaram a desmatar para desenvolver suas culturas e criar animais (DEUS; BAKONYI, 2012). 
Durante a palestra também foram apresentadas questões relativas à Revolução Industrial, o estopim na geração de diversos problemas, devido à alta produtividade visando a atender à demanda de consumo da população. Este processo exterminou milhares de pessoas e danificou o meio ambiente por meio de vazamentos de poluentes químicos nocivos, ocasionando a poluição de corpos d'água e do solo (LEAL; FARIAS; ARAÚJO, 2008). Na reflexão provocada ficou claro que este foi o ponto de partida para que alguns países passassem a discutir e buscar formas de minimizar os danos causados, além de traçar estratégias de prevenção para evitar catástrofes futuras (POTT; ESTRELA, 2017).

Nesse contexto, discutiu-se com os grupos focais que há esforços visando a minimizar os impactos causados, visto que há problemas diversos que não estão apenas relacionados ao meio ambiente, mas também a questões sociais (ANTUNES; NASCIMENTO; QUEIROZ, 2017). Em se tratando de questões relacionadas à desigualdade e pobreza, é preciso associar diversos fatores (políticos, culturais, institucionais e históriCos), que revelam uma sociedade estruturalmente desigual (PETERMANN; CRUZ, 2017). Nesse momento da discussão proporcionou-se uma reflexão acerca de quais medidas estavam sendo tomadas para ampliar essa consciência, a partir da mudança de hábitos da população. Os estudantes citaram algumas medidas, como: "respeitar a natureza", "repensar o consumo", "ter mais consciência em relação ao uso da água e energia", "reduzir e descartar corretamente os resíduos", "promoção da reciclagem" e "plantio de árvores". Segundo eles, são medidas simples que podem ajudar a minimizar tais problemas.

Durante a participação ativa dos estudantes, relatando acontecimentos importantes referentes ao tema sustentabilidade, observou-se que eles estão atentos às questões relacionadas a esta questão, pois demonstraram alguns conhecimentos no diagnóstico inicial, reforçados na palestra. O diálogo dos participantes, nesta etapa, foi fundamental para a troca de experiências e apontamentos de medidas viáveis em diversas problemáticas levantadas, além das contribuições relevantes referentes a alguns acontecimentos históricos.

Assim, observou-se a boa interação dos estudantes dos diferentes níveis de ensino, a partir de suas expressões de sentimentos e de reações apresentadas. Ao final da pesquisa foi solicitado que, voluntariamente, falassem a respeito de sua experiência neste estudo. Dessa forma, foi notável que os estudantes do Mestrado (Grupo 1), que estão no campo da pesquisa há mais tempo, destacaram-se no discurso das relevantes práticas sustentáveis que se deve adotar, como "redução do consumismo", "melhor distribuição de renda", "valorização da produção e do comércio local", "valorização da produção orgânica", entre outras citadas. Vale ressaltar que o mesmo grupo destacou-se também na avaliação diagnóstica, possivelmente por fazerem parte de uma formação continuada na área da sustentabilidade.

Já os estudantes da Graduação (Grupo 2) apresentaram alguns pontos sensíveis no diagnóstico, porém as dúvidas foram sanadas durante a palestra interativa, com excelente participação. Importa ressaltar que eles também desenvolvem competências e habilidades ao longo de sua formação acadêmica, com a iniciação e desenvolvimento da pesquisa científica, formando pensamentos críticos e reflexivos nestas intervenções, podendo ser influenciados nas tomadas de decisão, no direcionamento de suas ações e 
objetivos. Ademais, observou-se que as falas foram direcionadas ao fato de que serão potenciais educadores ambientais, uma vez que estão cursando uma Licenciatura. Foi citada a importância de aprenderem a elaborar e aplicar oficinas de educação ambiental envolvendo as temáticas deste estudo.

Em se tratando dos estudantes do Ensino Médio (Grupo 3), também foram observados alguns pontos sensíveis no diagnóstico. Na palestra interativa, porém, os aspectos como o raciocínio crítico e interpretativo dos alunos tornou-se mais aprofundado por meio de provocações, configurando-se como um momento em que interesses, necessidades, curiosidades e saberes diversos se equipararam em relação aos saberes sistematizados. Neste grupo focal percebeu-se grande curiosidade pelos assuntos abordados, contribuindo para uma maior problematização.

Diante dos resultados obtidos não se considera a relevância desse estudo apenas na comparação nos diferentes níveis de ensino (Educação Básica e Ensino Superior), mas sim na possibilidade de proporcionar momentos de diálogo e reflexão sobre sustentabilidade com a interação de diferentes grupos. O principal aspecto observado nesta proposta foi que sensibilizar as pessoas é uma forma de trabalhar com suas emoções, favorecendo a mudança de valores (SILVA; SANTOS; TERÁN, 2019). Nesse sentido, os três grupos focais abordados nesta pesquisa podem tornar-se agentes multiplicadores de boas práticas, replicando as informações discutidas no intuito de provocar alterações de comportamento da comunidade, propiciando mudanças sociais significativas. Assim, essa formação de jovens multiplicadores pode ser considerada um mecanismo pedagógico de desenvolvimento, de forma integrada e sustentável (ADAIME et al., 2014).

Não obstante, é preciso, cada vez mais, fortalecer o diálogo relacionado à interação entre as questões ambientais, econômicas e sociais. Isto porque o Brasil passa por um momento político complexo, caracterizado por Layrargues (2020) como um devastador tsunami de retrocessos ambientais que caminha na direção da extinção de instrumentos públicos de proteção ambiental. $O$ autor relata a preocupação com o drama social ecopolítico brasileiro que pode estagnar a educação ambiental, seguindo configurando um sujeito ecológico conservador e oportunizando a mudança para a formação de um sujeito irreverentemente ecopolítico.

Nesse contexto, é indispensável o fortalecimento de uma visão crítica dessas questões no ensino formal, propondo novas metodologias de abordagem na direção da formação de cidadãos mais conscientes de seus direitos e deveres. Muitos estudantes ainda estão distantes de compreender a importância do seu voto, assim como a função e o dever que seu candidato tem perante a sociedade e, sobretudo, que esta pode ser transformada pelas pessoas a partir da fiscalização e da cobrança do cumprimento da legislação vigente.

\section{CONSIDERAÇÕES FINAIS}

A educação brasileira, por ser dividida em níveis e modalidades de ensino, possui características e objetivos específicos. A partir deste estudo foi possível diagnosticar o conhecimento de estudantes dos dois níveis de ensino, Educação Básica (Ensino Médio) e Superior (Graduação e Pós-Graduação), referente ao tema sustentabilidade. A partir do diagnóstico, promoveu-se uma intervenção, oportunizando o diálogo e a reflexão 
acerca de problemas ambientais e sociais ao longo da História. Esse diálogo realizado entre estudantes foi muito positivo, principalmente em relação ao compartilhamento de conhecimentos e experiências, estimulando-se novos pensamentos voltados à sustentabilidade, com sensibilização e equilíbrio com o meio ambiente.

Essa nova perspectiva é fundamental no atual cenário brasileiro, entre tantos conflitos políticos que afetam, direta e indiretamente, as questões sociais, econômicas e ambientais. Despertando-se tais reflexões, foi possível realizar um exercício a respeito da percepção da necessidade urgente da promoção de condições mais dignas de vida para as gerações atuais e futuras. Além disso, a educação é um caminho para a formação de cidadãos mais críticos, aptos a efetivamente exercerem sua cidadania, por meio do voto consciente, da fiscalização e cobrança ao poder público nas esferas municipal, estadual e federal. Dessa forma, espera-se que as questões relacionadas à sustentabilidade continuem sendo discutidas no ensino formal com transposição para o ensino não formal, propiciando melhorias para a sociedade com vistas à preservação do meio ambiente.

\section{REFERÊNCIAS}

ADAIME, Martha Boher; BOTEGA, Marcia Palma; PRESTES, Osmar Damian; ZANELLA, Renato. Agrotóxicos e meio ambiente: inserção do tema na escola através de uma abordagem interdisciplinar. Ciência e Natureza, v. 36, n. 2, p. 250-257, 2014.

ALMEIDA, Maria Angélica Randoli; WILSON, Ana Maria Miranda Martins; PETERLINI, Maria Angélica Sorgini. Avaliação do descarte de resíduos de medicamentos em unidades pediátricas. Revista da Escola de Enfermagem da USP, v. 50, n. 6, p. 922-928, out. 2016.

ANDRADE, Luiz Fernando Dantas; SANTOS, Adyson Barboza. Caracterização dos impactos ambientais causados pela indústria de petróleo. In: CONGRESSO NACIONAL DE ENGENHARIA DE PETRÓLEO, GÁS NATURAL E BIOCOMBUSTÍVEIS, 1., 2015, Campina Grande. Anais [...]. Campina Grande: Realize, 2015, v. 1, p. 1-7. Disponível em: http://www.editorarealize.com.br/revistas/conepetro/trabalhos/Modalidade_4datahora_29_03_2015_17_16_10_idinscrito_1852_33fabc2fc8ef90605aeed46bf95df78c.pdf. Acesso em: 3 dez. 2019.

ANTUNES, Jeferson; NASCIMENTO, Verônica Salgueiro do; QUEIROZ, Zuleide Fernandes de. Narrativa crítica acerca do desenvolvimento sustentável: Quais relações podemos estabelecer? Remea, Revista Eletrônica do Mestrado em Educação Ambiental, v. 34, n. 2, p. 57-75, ago. 2017.

BARBIER, René. A pesquisa-ação. 1. ed. Brasília: Liber Livro, 2007. 159 p.

BARBOSA, Gisele Silva. O desafio do desenvolvimento sustentável. Revista Visões, v. 1, n. 4, p. 1-11, jan./ jun. 2008.

BARRETO, Leopoldo Melo; VILAÇA, Maria Teresa Machado. Controvérsias e consensos em educação ambiental e educação para o desenvolvimento sustentável. Research, Society and Development, v. 7, n. 5, p. 1-18, 2018.

BONOTTO, Elisa; RUSCHEL, Daiana; JACQUES, Jocelise Jacques de; LINDEN, Júlio Carlos de Souza van Der. A sustentabilidade como um wicked problem. Brazilian Journal of Development, v. 4, n. 6, p. 3.335-3.351, out./dez. 2018.

BRASIL. Lei № 12.305, de 2 de agosto de 2010. Institui a Política Nacional de Resíduos Sólidos; altera a Lei no 9.605, de 12 de fevereiro de 1998; e dá outras providências. Brasília: Senado Federal, 2010. Disponível em: http://www2.mma.gov.br/port/conama/legiabre.cfm?codlegi=636. Acesso em: 20 nov. 2019.

BRASIL. Lei $N^{\circ}$ 9.795, de 27 de abril de 1999. Dispõe sobre a educação ambiental, institui a Política Nacional de Educação Ambiental e dá outras providências. Brasília: Senado Federal, 1999. Disponível em: http://www.planalto.gov.br/ccivil_03/leis/19795.htm. Acesso em: 2 dez. 2019.

CAMARGO, Janielly Carvalho; VELHO, Luiz Felipe Machado. Reflexões sobre o consumo sustentável. Remea, Revista Eletrônica do Mestrado em Educação Ambiental, v. 29, n. 1, p. 1-19, dez. 2012. 
CÉZAR-MATOS, Arlinda Matos. A pegada ecológica como ferramenta de percepção do ecossistema urbano. In: FÓRUM INTERNACIONAL DE RESÍDUOS SÓLIDOS, 2., 2009. Porto Alegre. Anais [...]. Porto Alegre: Instituto Venturini, 2009. Disponível em: http://www.institutoventuri.org.br/download/artigos/Pegada\%20Ecologica[caseSantander].pdf. Acesso em: 7 nov. 2019.

DEUS, Rafael Mattos de; BAKONYI, Sonia Maria Cipriano. O impacto da agricultura sobre o meio ambiente. Revista Eletrônica em Gestão, Educação e Tecnologia Ambiental, v. 7, n. 7, p. 1.306-1.315, ago. 2012.

DIEGUES, Antonio Carlos. S. Desenvolvimento sustentável ou sociedades sustentáveis: da crítica dos modelos aos novos paradigmas. São Paulo em Perspectiva, v. 6, n. 1-2, p. 22-29, jan./jun. 1992.

EFFTING, Tânia Regina. Educação ambiental nas escolas públicas: realidade e desafios. 2007. 90 f. Monografia (Especialização em Planejamento Para o Desenvolvimento Sustentável) - Centro de Ciências Agrárias, Universidade Estadual do Oeste do Paraná - Campus de Marechal Cândido Rondon, Marechal Cândido Rondon, 2007.

ELKINGTON, John; ROWLANDS, Lan H. Cannibals with forks: The triple bottom line of 21st century business. Alternatives Journal, v. 25, n. 4, p. 42-43, 1999.

FOLADORI, Guillermo. Avanços e limites da sustentabilidade social. Revista Paranaense de Desenvolvimento, n. 102, p. 103-113, jan./jun. 2002.

GONDIM, Sônia Maria Guedes. Grupos focais como técnica de investigação qualitativa: desafios metodológicos. Paidéia, v. 12, n. 24, p. 149-161, 2003.

HORN, Bibiana Silveira; OLIVEIRA, Jéssica; PETTER, Daniela; WALDMAN, Ricardo Libel; RIBEIRO, Vinícius Gadis; SILVEIRA, André Luis Marques da. O uso do triple bottomline como uma ferramenta alternativa de sustentabilidade empresarial na sociedade de risco. In: SIMPÓSIO BRASILEIRO DE DESIGN SUSTENTÁVEL, 4., 2014. Porto Alegre. Anais [...]. Porto Alegre: UniRitter, 2014.

KAUARK, Fabiana da Silva; MANHÃES, Fernanda Castro; MEDEIROS, Carlos Henrique. Metodologia da pesquisa: guia prático. Itabuna: Via Litterarum, 2010. 89 p.

LAYRARGUES, Philippe Pomier. Manifesto por uma educação ambiental indisciplinada. Ensino, Saúde e Ambiente, n. especial, p. 44-88, 2020.

LEAL, Georla Cristina Souza de Gois; FARIAS, Maria Sallydelandia Sobral de; ARAÚJO, Aline de Farias. O processo de industrialização e seus impactos no meio ambiente urbano. Qualitas Revista Eletrônica, v. 7, n. 1, p. 1-11, ago. 2008.

LIMA, Gustavo da Costa. O discurso da sustentabilidade e suas implicações para a educação. Ambiente e Sociedade, v. 6, n. 2, jul./dez. 2003.

MOREIRA JÚNIOR, Danilo P.; SILVA, Cleyton Martins da; BUENO, Cecilia; CORRÊA, Sérgio M.; ARBILLA, Graciela. Determinação de gases do efeito estufa em cinco capitais de diferentes biomas brasileiros. Revista Virtual de Química, v. 9, n. 5, p. 2.032-2.051, out. 2017.

OLIVEIRA, Tina. Estilo de vida sustentável, 2013. In: MINISTÉRIO DO MEIO AMBIENTE. Disponível em: https://www.mma.gov.br/informma/item/9384-estilo-de-vida-sustentável. Acesso em: 2 dez. 2019.

PETERMANN, Vânia; CRUZ, Paulo Marcio da. (Des)Igualdade e sustentabilidade social: do patrimônio ambiental todos são herdeiros. Justiça do Direito, v. 31, n. 1, p. 24-44, abr. 2017.

PHILIPPI JUNIOR, Arlindo; PELICIONI, Maria Cecília Focesi (org.). Educação ambiental e sustentabilidade. 2. ed. Barueri: Editora Manole, 2014. 1.004 p.

PINTO, Gláucia Maria Ferreira; SILVA, Kelly Regina da; PEREIRA, Rosana de Fátima Altheman Bueno; SAMPAIO, Sara Issa. Estudo do descarte residencial de medicamentos vencidos na região de Paulínia (SP), Brasil. Engenharia Sanitária e Ambiental, v. 19, n. 3, p. 219-224, set. 2014.

POTT, Crisla Maciel; ESTRELA, Carina Costa. Histórico ambiental: desastres ambientais e o despertar de um novo pensamento. Estudos Avançados, v. 31, n. 89, p. 271-283, abr. 2017.

PORTILHO, Fátima. Consumo sustentável: limites e possibilidades de ambientalização e politização das práticas de consumo. Cadernos Ebape.br, Fundação Getúlio Vargas, Rio de Janeiro, p. 1-12, ago. 2005.

RAMIRES, Maiara Figueiredo. Emissão de gases de efeito estufa e potencial de aquecimento global em sistemas de culturas intercalares ao tungue (Aleurites fordii). 2014. 81 f. Dissertação (Mestrado em Ciência do Solo) - Universidade Federal de Santa Maria, Santa Maria, 2014.

RIBEIRO, Luiz Gustavo Gonçalves; ROLIM, Neide Duarte. Planeta água de quem e para quem: uma análise da água doce como direito fundamental e sua valoração mercadológica. Revista Direito Ambiental e Sociedade, Rio Grande do Sul, v. 7, n. 1, p. 7-33, out. 2017.

ROOS, Alana; BECKER, Elsbeth Leia Spode. Educação ambiental e sustentabilidade. Revista Eletrônica em Gestão, Educação e Tecnologia Ambiental, v. 5, n. 5, p. 857-866, ago. 2012. 
SEGALA, Mariana. Água: a escassez na abundância. Planeta Sustentável. Guia Exame Sustentabilidade. 2012. p. 1-4. Disponível em: https://issuu.com/exame/docs/guia-exame-sustentabilidade-2012.

SILVA, Fabrícia Souza; SANTOS, Sammya Danielle Florêncio; TERÁN, Augusto Fchín. O jardim zoológico do CIGS: um espaço estratégico para despertar a sensibilização ambiental. Reamec, Revista da Rede Amazônica de Educação em Ciências e Matemática, v. 7, n. 2, p. 280-292, 2019.

SILVA, Saionara da; FERREIRA, Elaine; ROESLER, Célio; BORELLA, Diego; GELATTI, Elisangela; BOELTER, Fernando; MENDES, Patrick. Os 5 Rs da sustentabilidade. In: SEMINÁRIO DE JOVENS PESQUISADORES EM ECONOMIA \& DESENVOLVIMENTO, 5., 2017. Santa Maria. Anais [...]. Santa Maria: Universidade Federal de Santa Maria, 2017.

SOUZA, Luciana Oliveira Alves de. Plano de gerenciamento de resíduos sólidos - PGRS. Brasília: Scom Ambiental, 2017. 54 p.

TIRIBA, Lea. Desemparedamento da infância: a escola como lugar de encontro com a natureza. 2. ed. Rio de Janeiro: Alana Editora, 2018. 59 p.

THIOLLENT, Michel. Metodologia da pesquisa-ação. 18. ed. São Paulo: Cortez, 2011.

VAN BELLEN, Hans Michael. Indicadores de sustentabilidade: uma análise comparativa. 2. ed. Rio de Janeiro: FGV. 2006. 253 p.

VEIGA, Luciana; GONDIM, Sônia Maria Guedes. A utilização de métodos qualitativos na ciência política e no marketing político. Opinião Pública, v. 7, n. 1, 2001. 